Proc. Indian Acad. Sci. (Earth Planet. Sci.), Vol. 100, No. 3, September 1991, pp. 235-253.

(C) Printed in India.

\title{
Cumulus convection and lateral boundary conditions in a limited area model
}

\author{
E N RAJAGOPAL and S S SINGH \\ Indian Institute of Tropical Meteorology, Pune 411008, India
}

MS received 18 February 1991; revised 9 August 1991

\begin{abstract}
Three versions of Kuo's cumulus parameterization have been tested in a limited area model to investigate their comparative performances. Results show that the version of Anthes produces better forecasts than those produced by other versions. To identify a suitable scheme of lateral boundary conditions for the limited area model, impact of two time-invariant and two time-dependent boundary conditions have been examined. The forecasts suggest that the time-dependent tendency modification scheme, based on large-scale tendencies obtained from observed data, is a better boundary scheme for the model. Furthermore, the forecast produced with the revised version of the model incorporating improved versions of Kuo's scheme and lateral boundary conditions shows an overall improvement.
\end{abstract}

Keywords. Limited area model; cumulus convection; lateral boundary conditions; sponge damping; Kuo's cumulus parameterization.

\section{Introduction}

Cumulus convection is considered to be one of the important facets of numerical modelling for short and medium range weather prediction, particularly over the monsoon region. Another important component of modelling which is peculiar to limited area models, is the specification of lateral boundary conditions.

In the present paper, an attempt was made to study different versions of Kuo's scheme and lateral boundary conditions in a limited area model (Singh et al 1990) to identify suitable schemes of convection and boundary conditions. Comparatively better schemes that emerged from the above investigation are incorporated in the model to produce $48 \mathrm{~h}$ forecasts.

The paper presents different versions of Kuo's scheme and lateral boundary conditions. The forecast produced with the improved version of the model is discussed.

\section{Description of the model}

The model is a regional six-level primitive equation model in $\sigma$-coordinates. The model is staggered in both vertical and horizontal directions. Arakawa's $B$-type of staggering was used in the horizontal direction. The six sigma levels were close to 950 , $850,700,500,300$ and $150 \mathrm{hPa}$. The top of the model was fixed at $100 \mathrm{hPa}$. The horizontal domain extends from $10^{\circ} \mathrm{S}$ to $40^{\circ} \mathrm{N}$ and $50^{\circ} \mathrm{E}$ to $120^{\circ} \mathrm{E}$. The horizontal domain had $45 \times 33$ grid points on a Mercator projection with $150 \mathrm{~km}$ as grid length.

The lateral boundary conditions are given in $\S 5$. In the vertical, the boundary 
condition $\dot{\sigma}=0$ at $\sigma=0$ and $\sigma=1$ was used. Mass, energy, potential temperature and the variance of potential temperature conserving schemes (Arakawa and Mintz 1974; Arakawa and Lamb 1977) for space derivatives were used. The horizontal advection terms in the momentum equations were computed with fourth-order accuracy finite difference scheme (Arakawa's 13-point Jacobian scheme). The other terms were computed with a second-order accuracy finite difference scheme. For time integration, a leap frog scheme with Asselin (1972) time filter was used with a time-step of 3 minutes. The physical processes incorporated in the model are: large-scale condensation, dry convective adjustment, horizontal and vertical diffusion, sensible heat supply and evaporation over the sea. Three versions of convection were incorporated in the model. A detail description of the model may be found in Singh et al (1990).

\section{Data}

The FGGE IIIb grid point data of 12 GMT 7 July 1979 were used as input to the model for all numerical experimentations. The dominant synoptic feature was an intense monsoon depression centred over the head Bay of Bengal on 7 July. This system moved initially westward and subsequently northwestward and dissipated on 9 July.

\section{Study on cumulus convection}

The cumulus parameterization scheme of Kuo $(1965,1974)$ has been widely used in large-scale numerical weather prediction models due to its simple formulation and computational economy. Several investigators showed that the classical scheme of Kuo (1965) underestimated rainfall rates. Furthermore, it was noted that there was a disproportionate partitioning of the available moisture supply into moistening and heating. Kuo (1974) recognized the shortcomings of his earlier scheme and introduced a more realistic division of the moisture by bringing in a moistening parameter $b$. Considerable attention has been focussed on improving the performance of Kuo's (1974) scheme by trying to find the most appropriate value of the moistening parameter $b$. In the following section an outline of the Kuo's scheme is given.

\subsection{An outline of the Kuo's scheme}

In the Kuo's scheme of cumulus parameterization the heating and vertical flux of moisture is invoked only if the sounding is conditionally unstable and the net convergence of moisture is positive. Following Kanamitsu et al (1983), the large scale supply of moisture (net convergence of moisture) $I_{L}$ is given by

$$
I_{L}=\int_{\sigma_{B}}^{\sigma_{r}}(\partial q / \partial t) \mathrm{d} \sigma .
$$

Krishnamurti et al (1983a) introduced an additional source of moisture supply $\eta I_{L}$ which is a non-measurable mesoscale (or sub-grid scale) suppiy. The term $\eta I_{L}$ was introduced to provide sufficient moisture supply in the vertical column to account 
for the observed rainfall rates and moistening. The total moisture supply was expressed by

$$
I=I_{L}(1+\eta)
$$

$\eta$ is known as the mesoscale convergence parameter. Following Kuo (1965), the maximum amount of moisture supply required to produce a grid square cloud was expressed by

$$
Q=-\int_{\sigma_{B}}^{\sigma_{T}}\left(q_{s}-q\right) \mathrm{d} \sigma-\frac{C_{p}}{L} \int_{\sigma_{B}}^{\sigma_{T}}\left(T_{s}-T\right) \mathrm{d} \sigma .
$$

The first term on the right side is denoted as $Q_{q}$ and the second term as $Q_{\theta}$. The terms $Q_{q}$ and $Q_{\theta}$ respectively denote the supply needed for moistening and heating of a unit column. Introduction of a parameter $b$ following Kuo (1974), the rainfall rate $R$ and moistening rate $M$ may be expressed by

$$
\begin{aligned}
& R=I_{L}(1+\eta)(1-b), \\
& M=I_{L}(1+\eta) b .
\end{aligned}
$$

Following Kuo (1974), the two additional parameters $a_{\theta}$ and $a_{q}$ may be expressed by

$$
\begin{aligned}
& a_{\theta}=\frac{I(1-b)}{Q_{\theta}}=\frac{I_{L}(1+\eta)(1-b)}{Q_{\theta}}, \\
& a_{q}=\frac{I b}{Q_{q}}=\frac{I_{L}(1+\eta) b}{Q_{q}} .
\end{aligned}
$$

In this formulation there are two unknown parameters $b$ and $\eta$ that are to be determined.

The heating and moistening by clouds are proportional to the temperature and humidity difference between the model cloud and the environment. Consequently the heating and moistening at each level are expressed as

$$
\begin{aligned}
& \partial T / \partial t=a_{\theta}\left(T_{s}-T\right), \\
& \partial q / \partial t=a_{q}\left(q_{s}-q\right) .
\end{aligned}
$$

From (6) and (7), $a_{\theta}$ and $a_{q}$ are determined if $b$ and $\eta$ are known and thus the parameterization is closed.

In the following section we shall show how $b$ and $\eta$ are determined by different versions of Kuo's scheme.

\subsection{Three versions of Kuo's scheme}

(i) Kuo (1974) version (KU74): This is essentially the earlier Kuo (1974) scheme of parameterization. The parameters $b$ and $\eta$ are set zero. The coefficients $a_{\theta}$ and $a_{q}$ are determined as follows:

$$
\begin{aligned}
& a_{\theta}=I_{L} / Q_{\theta}, \\
& a_{q}=0 .
\end{aligned}
$$


The above formulation for computation of $a_{\theta}$ and $a_{q}$ was used by Krishnamurti et al (1980). This version will hereafter be referred to as KU74.

(ii) Anthes (1977) version (AN77): The parameter $\eta$ is set zero. The parameter $b$ is computed following Anthes (1977).

$$
b=\left\{\begin{array}{ll}
\left(\frac{1-\langle\mathrm{RH}\rangle}{1-\mathrm{RH}_{c}}\right)^{n} & \text { when }\langle\mathrm{RH}\rangle>\widetilde{\mathrm{R}} \mathrm{H}_{c} \\
1 & \text { when }\langle\mathrm{RH}\rangle \leqslant \mathrm{RH}_{c}
\end{array},\right.
$$

where $\langle\mathrm{RH}\rangle$ is the mean relative humidity in the cloud layer and $\mathrm{RH}_{c}$ is the critical relative humidity below which there is only moistening. The values, $\mathrm{RH}_{c}=0.5$ and $n=3$ are used in the present study.

The heating and moistening rates were calculated following the usual Kuo (1974) scheme. The coefficients $a_{\theta}$ and $a_{q}$ are determined by

$$
\begin{aligned}
& a_{\theta}=(1-b) I_{L} / Q_{\theta}, \\
& a_{q}=b I_{L} / Q_{q} .
\end{aligned}
$$

This version will hereafter be referred to as AN77.

(iii) Krishnamurti et al (1983) version (KR83): Krishnamurti et al (1983a) proposed a closure for $b$ and $\eta$ by a screening multiple-regression analysis of GATE observations. The normalized heating and moistening $R / I_{L}$ and $M / I_{L}$ were regressed against a number of large-scale variables. Based on GATE observations, significant correlations for moistening and heating were noted by them from the following relations,

$$
\begin{aligned}
& M / I_{L}=a_{1} \zeta+b_{1} \bar{\omega}+c_{1}, \\
& R / I_{L}=a_{2} \zeta+b_{2} \bar{\omega}+c_{2} .
\end{aligned}
$$

where $\zeta$ is the relative vorticity at $700 \mathrm{hPa}$ and $\bar{\omega}$ is the vertically-averaged vertical $p$-velocity. $a_{1}, a_{2}, b_{1}, b_{2}, c_{1}$ and $c_{2}$ are coefficients of regression. Magnitudes of these coefficients are given by Arunkumar (1989). Expressions for $b$ and $\eta$ can be obtained from (4), (5), (15) and (16).

$$
\begin{aligned}
& b=\frac{a_{1} \zeta+b_{1} \bar{\omega}+c_{1}}{\left(a_{1}+a_{2}\right) \zeta+\left(b_{1}+b_{2}\right) \bar{\omega}+\left(c_{1}+c_{2}\right)}, \\
& \eta=\left(a_{1}+a_{2}\right) \zeta+\left(b_{1}+b_{2}\right) \bar{\omega}+\left(c_{1}+c_{2}\right)-1 .
\end{aligned}
$$

Thus the values of $b$ and $\eta$ could be determined with model values of $\zeta$ and $\bar{\omega}$. The coefficients $a_{\theta}$ and $a_{q}$ were then obtained by

$$
\begin{aligned}
& a_{\theta}=I_{L}(1+\eta)(1-b) / Q_{\theta}, \\
& a_{q}=I_{L}(1+\eta) b / Q_{q} .
\end{aligned}
$$

The scheme will be referred to as KR83.

\subsection{Numerical experiments}

Two numerical experiments using the three versions outlined in the previous section were made. In the first experiment (EX1), following Kanamitsu et al (1983) the 
conditions to be satisfied for invoking convection are: (i) conditionally unstable atmosphere, (ii) positive moisture convergence in the cloud layer and (iii) environmental mean relative humidity in the cloud layer exceeds a critical value of $80 \%$. In the second experiment (EX2) convection is invoked if conditions (i) and (ii) of EX1 are satisfied. No constraint is imposed on mean relative humidity.

In both the experiments the time-invariant lateral boundary conditions were used.

\subsection{Discussion}

In both experiments the model was integrated up to $48 \mathrm{~h}$ using input data of 12 GMT 7 July 1979.

In the first experiment (EX1) the forecast results of KU74, AN77 and KR83 were found very similar. In the second experiment (EX2) both KU74 and KR83 schemes produced spurious results. Hence, the forecast results of KU74 of EX1 (EX1/KU74) and AN77 of EX2 (EX2/AN77) are discussed below for comparison.

(i) $850 \mathrm{hPa}$ wind: Figure 1 shows $48 \mathrm{~h}$ predicted $850 \mathrm{hPa}$ winds of EX1/KU74 and EX2/AN77 schemes. The observed winds of 12 GMT 9 July 1979 are also shown in the same figure for comparison. It can be seen that in both the experiments the circulation features are reasonably well-predicted, particularly the cyclonic circulations associated with the depression, circulations around the equator and the cross-equatorial flow. However, the easterlies to the north and westerlies to the south of the depression are found to be weaker. It can also be seen that the westerlies off the west coast are overpredicted by $10-15 \mathrm{kt}$.

(ii) Rainfall: The predicted rainfall rates (12-36h) of EX1/KU74 and EX2/AN77 are shown in figure 2 . The observed rainfall during the $24 \mathrm{~h}$ period ending at $00 \mathrm{GMT}$ 9 July 1979 (Source: Krishnamurti et al 1983b) are also shown in the same figure. In general, the areal distribution of rainfall is predicted better in EX2/AN77. The predicted rainfall rates associated with the depression are underpredicted in both the experiments. Grell et al (1991), in their semiprognostic tests in middle latitude with three versions of Kuo's scheme noticed underprediction of heating and moistening rates. They noted the need to include mesoscale moisture convergence to correctly predict the heating and moistening rates in large-scale models.

In EX1/KU74 the rainy area associated with the depression has two maxima, one of $20.6 \mathrm{~mm}$ at $20^{\circ} \mathrm{N}, 85^{\circ} \mathrm{E}$ and the other of $10.2 \mathrm{~mm}$ at $20^{\circ} \mathrm{N}, 76^{\circ} \mathrm{E}$. The observed rainfall maximum associated with the depression is $50 \mathrm{~mm}$ at $22^{\circ} \mathrm{N}, 80^{\circ} \mathrm{E}$. However, in EX2/AN77 the rainy area associated with the depression shows three rainfall maxima one of $12.4 \mathrm{~mm}$ at $18^{\circ} \mathrm{N}, 83^{\circ} \mathrm{E}$, other of $10.2 \mathrm{~mm}$ at $22^{\circ} \mathrm{N}, 78^{\circ} \mathrm{E}$ and another of $24.4 \mathrm{~mm}$ at $20^{\circ} \mathrm{N}, 75^{\circ} \mathrm{E}$.

(iii) Track of the depression: The predicted track of the depression of EX1/KU74 and EX2/AN77 is shown in figure 3. For comparison, the observed track of the depression is also shown in the figure. In can be seen that in both EX1/KU74 and EX2/AN77 the predicted tracks are to the north of the observed track and the movement is slower in the case of EX2/AN77 in the first $24 \mathrm{~h}$. In the next $24 \mathrm{~h}$ the depression moved westward in EX2/AN77 while in EX1/KU74 the movement is towards southwest. The $48 \mathrm{~h}$ forecast position of the depression is slightly to the south of the actual in EX2/AN77 while it is located far to the south-east in EX1/KU74. Thus, the westward movement of the depression in a $24-48 \mathrm{~h}$ period is better predicted in EX2/AN77. 


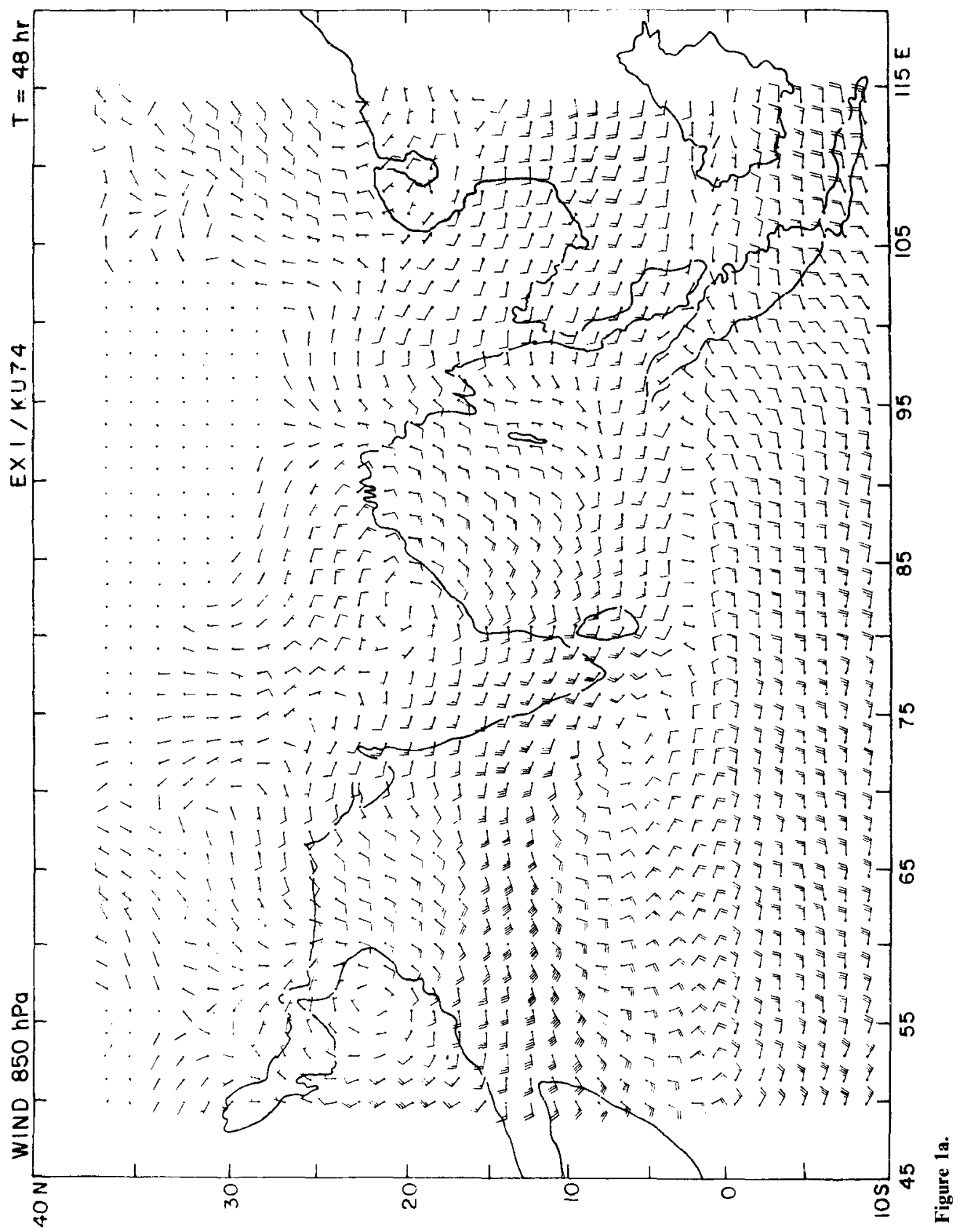




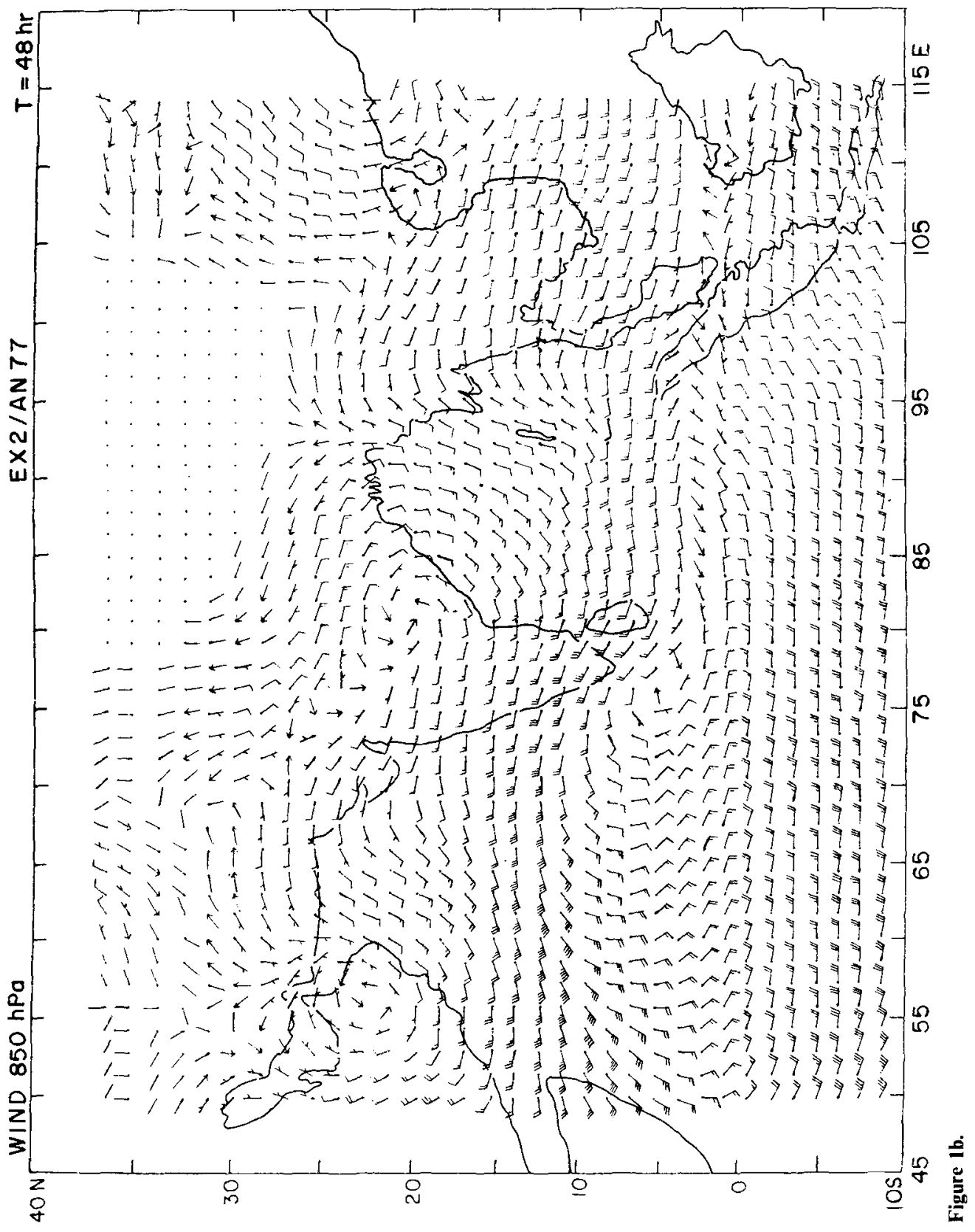




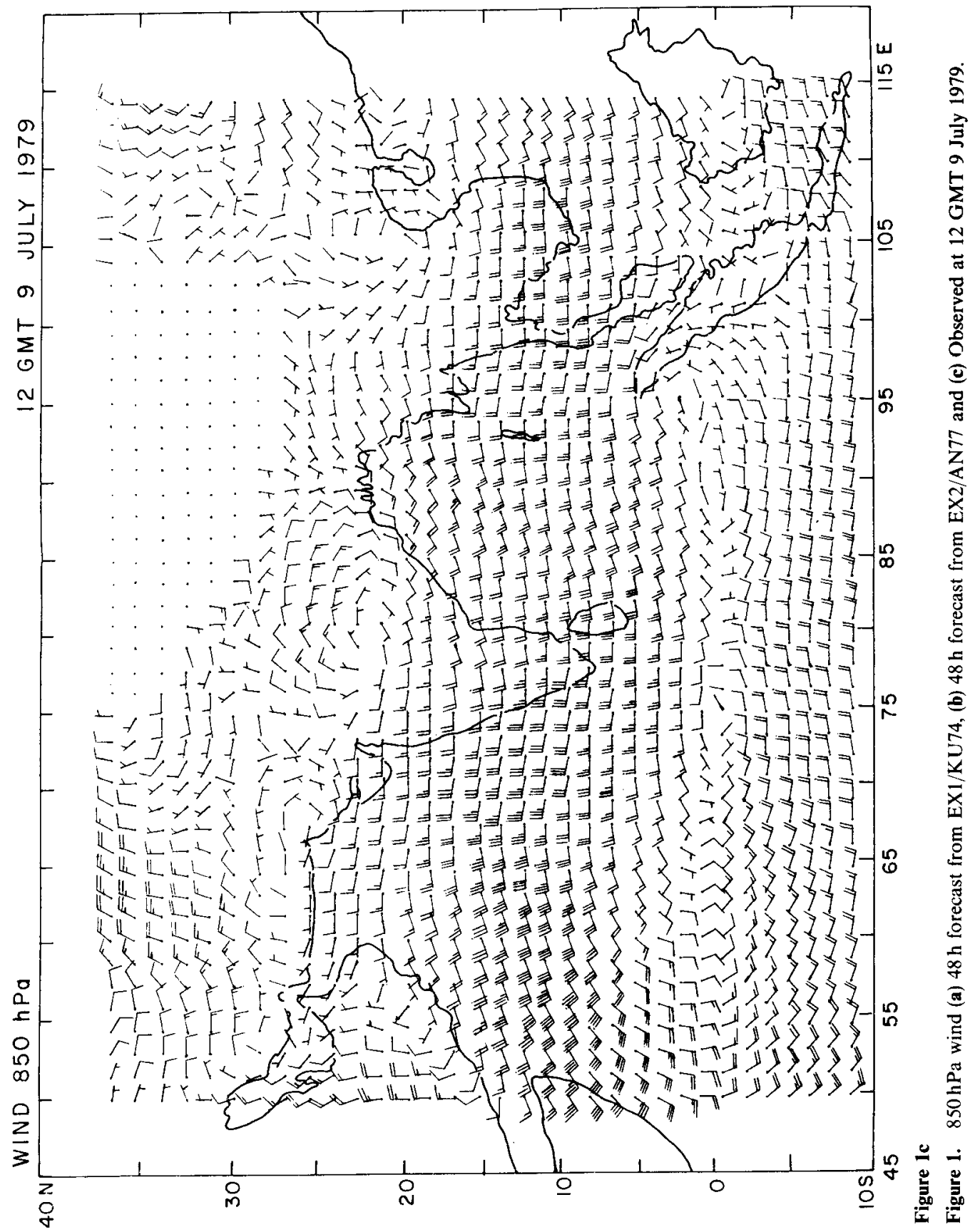



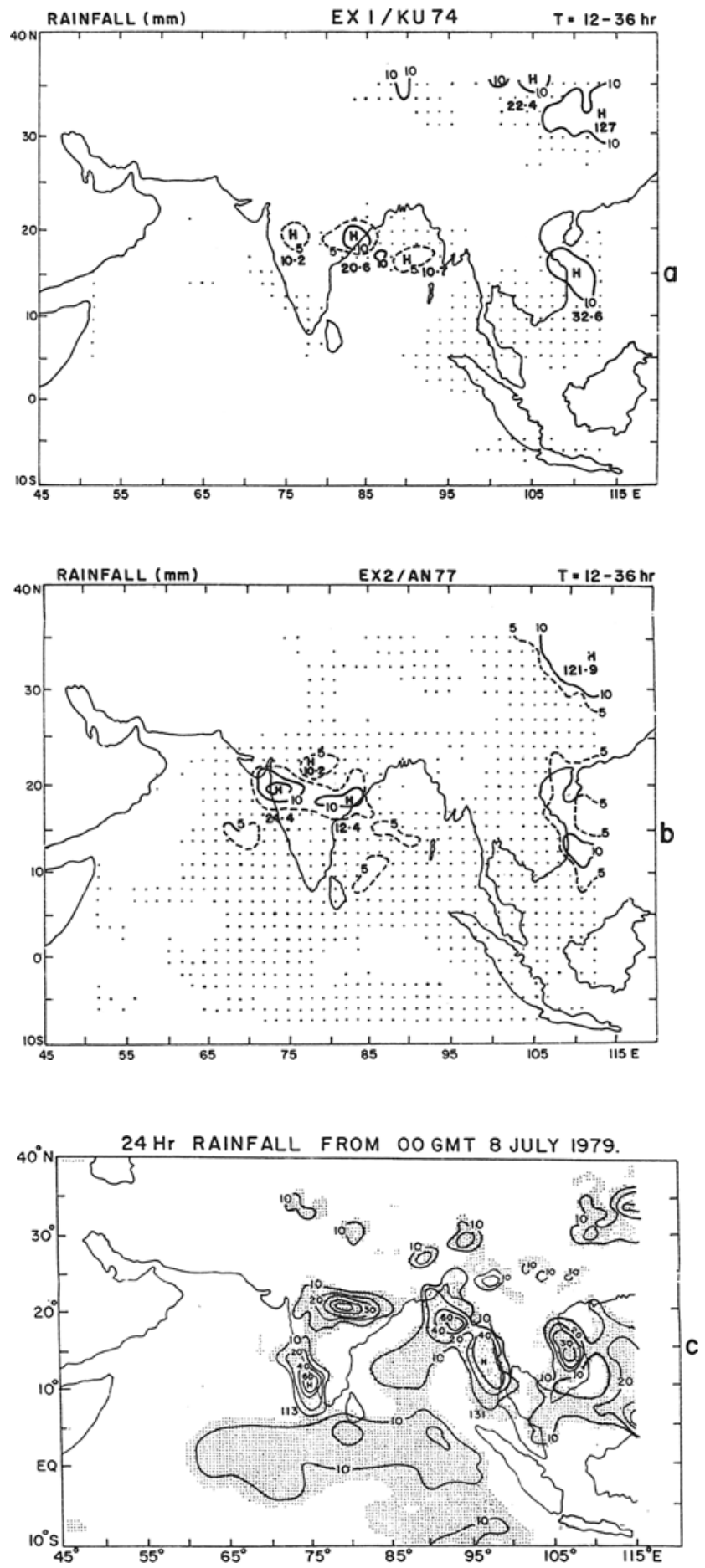

Figure 2. Rainfall (mm) (a) Forecast from EX1/KU74, (b) Forecast from EX2/AN77 and (c) Observed for the $24 \mathrm{~h}$ period ending $00 \mathrm{GMT} 9$ July 1979 (dots denote rainfall $<5 \mathrm{~mm}$ in (a) and (b) and rainy area in (c)). 


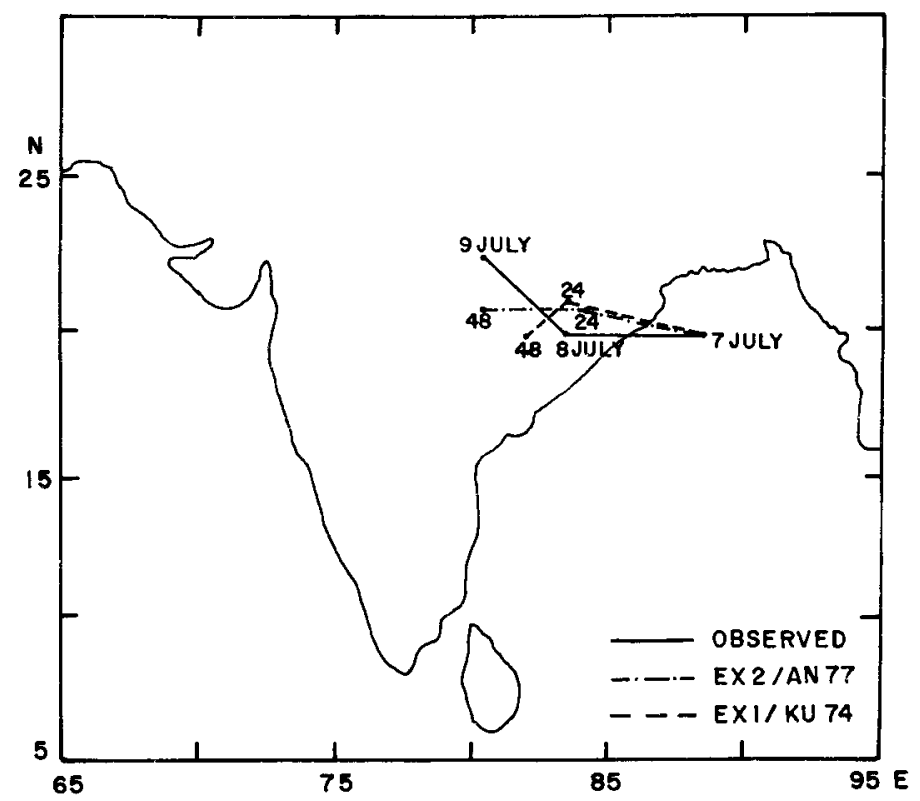

Figure 3. Predicted and observed tracks of the monsoon depression at $850 \mathrm{hPa}$ level.

Table 1. Predicted and observed phase speeds and positional errors of the monsoon depression at $850 \mathrm{hPa}$.

\begin{tabular}{|c|c|c|c|c|c|}
\hline \multirow[b]{2}{*}{$t(\mathrm{~h})$} & \multicolumn{3}{|c|}{ Phase speed $(\mathrm{km} / 24 \mathrm{~h})$} & \multicolumn{2}{|c|}{ Positional error $(\mathrm{km})$} \\
\hline & EX1/KU74 & EX2/AN77 & Observed & EX1/KU74 & EX2/AN77 \\
\hline $0-24$ & 570 & 490 & 560 & 110 & 110 \\
\hline $24-48$ & 200 & 405 & 420 & 310 & 190 \\
\hline
\end{tabular}

(iv) Phase speed and positional error: The predicted and observed phase speed of the monsoon depression and the positional errors are shown in table 1 . It can be seen that the predicted phase speed of the depression in the first $24 \mathrm{~h}$ of EX1/KU74 is comparable to the observed phase speed while the predicted phase speed of EX2/AN77 is less than the observed. In the next $24 \mathrm{~h}$ the predicted phase speed of EX1/KU74 is less than half of that observed while the phase speed of EX2/AN77 is comparable to the observed.

The positional error is the same for both EX1/KU74 and EX2/AN77 in the $24 \mathrm{~h}$ forecast. In the $48 \mathrm{~h}$ forecast the positional error is much higher in the case of EX1/KU74 scheme.

(v) RMS error: The root mean square (RMS) errors for $u$ and $v$ components of wind and geopotential height $(Z)$ at 850,500 and $200 \mathrm{hPa}$ for both EX1/KU74 and EX2/AN77 are shown in table 2. It can be seen that the RMS errors of $u, v$ and $Z$ are slightly less for EX2/AN77 at all the three levels in both 24 and $48 \mathrm{~h}$ forecasts. Slingo et al (1988), in their study of impact of various modified physical processes in 
Table 2. 24 and $48 \mathrm{~h}$ RMS errors of $u, v\left(\mathrm{~ms}^{-1}\right)$ and $Z(\mathrm{~m})$ at 850,500 and $200 \mathrm{hPa}$ levels for experiments EX1/KU74 and EX2/AN77.

\begin{tabular}{|c|c|c|c|c|c|}
\hline \multirow{2}{*}{$\begin{array}{l}\text { Level } \\
(\mathrm{hPa})\end{array}$} & \multirow[b]{2}{*}{ Variable } & \multicolumn{2}{|c|}{$24 \mathrm{~h}$} & \multicolumn{2}{|c|}{$48 \mathrm{~h}$} \\
\hline & & EX1/KU74 & EX2/AN77 & EX1/KU74 & EX2/AN77 \\
\hline \multirow{3}{*}{850} & $u$ & 3.6 & 3.6 & $5 \cdot 8$ & $5-6$ \\
\hline & $v$ & $3 \cdot 2$ & $3 \cdot 2$ & $3 \cdot 1$ & $3-0$ \\
\hline & $Z$ & $40 \cdot 8$ & $40 \cdot 6$ & $67 \cdot 2$ & $67 \cdot 9$ \\
\hline \multirow{3}{*}{500} & $u$ & $3 \cdot 1$ & $3 \cdot 0$ & $4 \cdot 6$ & $4 \cdot 7$ \\
\hline & $v$ & $2 \cdot 9$ & $2 \cdot 8$ & $3 \cdot 8$ & $3 \cdot 7$ \\
\hline & $Z$ & $47 \cdot 1$ & $45 \cdot 0$ & $86 \cdot 7$ & $83 \cdot 7$ \\
\hline \multirow{3}{*}{200} & $u$ & 5.0 & $4 \cdot 8$ & $7 \cdot 2$ & $7 \cdot 2$ \\
\hline & $v$ & 4.8 & 4.8 & 4.4 & $4-5$ \\
\hline & $Z$ & $73 \cdot 3$ & $71 \cdot 6$ & $122 \cdot 9$ & $120-4$ \\
\hline
\end{tabular}

the ECMWF model, showed that improvements in RMS wind errors at $850 \mathrm{hPa}$ could be found only after day 2 forecast.

From the above discussions on wind field, rainfall, track of the depression, phase speed, positional error and RMS error it can be inferred that EX2/AN77 is a better scheme for cumulus parameterization.

\section{Study of lateral boundary conditions}

The treatment of lateral boundaries is an important problem for regional NWP models. Over the years, a number of techniques for treating lateral boundaries have been tested. Sundstrom and Elvius (1979) and Davies (1983) have presented excellent reviews of commonly used lateral boundary conditions for regional models. In this study two time-invariant and two time-dependent lateral boundary conditions have been applied to examine their impact on model forecasts. In all experiments the EX1/KU74 version of convection has been incorporated.

\subsection{Four schemes for lateral boundary conditions}

(i) Fixed boundary conditions without sponge damping $\left(B_{1}\right)$ : In this, all the prognostic variables at the boundary were kept fixed throughout the period of integration i.e. the initial values were not modified at the boundary. This scheme will hereafter be referred to as the $B_{1}$ scheme.

(ii) Fixed boundary conditions with sponge damping $\left(B_{2}\right)$ : The sponge damping scheme of Perkey and Kreitzberg (1976) was adopted. Following their scheme the prediction of any dependent variable $X$ can be written as

$$
X_{n}(I)=X_{p}(I)+\left.W(I) \frac{\partial X m}{\partial t}\right|_{I} \Delta t
$$

where subscripts $n$ and $p$ denote the new value after the boundary condition is applied and a previous value at a former time and $m$ is the model-computed tendency. 
The values of the weighting coefficients $W$ were assigned as $0,0 \cdot 4,0 \cdot 7,0.9$ and $1 \cdot 0$ for the boundaries, the first, second, third and all other interior grid points respectively. We tested with a few other combinations of weighting coefficients and found that the above mentioned combination produced best result.

This scheme was a special case of the 'tendency modification scheme' of Perkey and Kreitzberg (1976) for cases where external large-scale tendencies at the boundaries were not available. This scheme will be referred to as the $B_{2}$ scheme.

(iii) Time-dependent boundary conditions without sponge damping $\left(B_{3}\right)$ : In this scheme the tendencies of the prognostic variables at the boundary were calculated from the 12 -hourly observed analyses and the boundary values were updated using the following relation,

$$
X_{n}=X_{p}+\left(\partial \mathrm{X}_{\mathrm{obs}} / \partial t\right) \Delta t
$$

where $X_{n}$ and $X_{p}$ are the new and previous values of any variable $X$, and $\partial X_{\text {obs }} / \partial t$ is the tendency calculated from the 12 -hourly observed data. This scheme hereafter will be referred to as the $B_{3}$ scheme:

(iv) Time-dependent boundary conditions with sponge-damping $\left(B_{4}\right)$ : The tendency modification scheme of Perkey and Kreitzberg (1976) was applied. In this scheme the prediction of any variable $X$ is given by

$$
X_{n}(I)=X_{p}(I)+\left.W(I) \frac{\partial X_{m}}{\partial t}\right|_{I} \Delta t+\left.[1-W(I)] \frac{\partial X_{1 \mathrm{~s}}}{\partial t}\right|_{I} \Delta t,
$$

where the subscripts $n$ and $p$ denote the new value and the previous values at a former time, $m$ denotes the model computed tendency and is denotes the large-scale tendency. The weighting coefficients $W(I)$ are the same given in $B_{2}$ scheme.

The large scale tendencies were computed from 12-hourly observed data. The scheme will be referred to as the $B_{4}$ scheme.

\subsection{Discussions of results}

The four lateral boundary conditions were applied in the regional model to examine their impact on model forecasts. In all experiments, the model was integrated up to $48 \mathrm{~h}$ using input data of 12 GMT 7 July 1979. The results are discussed below.

(i) RMS error: The RMS errors of $u$ and $v$ components of wind and geopotential height $(Z)$ at 850,500 and $200 \mathrm{hPa}$ level are shown in table 3 . It is evident that the RMS errors of the three variables at all three levels were less in the time-dependent scheme $B_{3}$ and $B_{4}$ compared to the time-invariant schemes. Among the time-dependent schemes, the RMS errors of $u$ and $v$ for $B_{4}$ scheme at all the levels were less than those of the $B_{3}$ scheme for a $24 \mathrm{~h}$ forecast, while for $Z$ it was higher at 850 and $500 \mathrm{hPa}$ and lower at $200 \mathrm{hPa}$ for the $B_{4}$ scheme. In a $48 \mathrm{~h}$ forecast the RMS error of $u$ and $v$ at 850 and $200 \mathrm{hPa}$ of $B_{4}$ were slightly higher than $B_{3}$, while it was the opposite at $500 \mathrm{hPa}$. The $48 \mathrm{~h}$ RMS error of $Z$ in $B_{4}$ was lower at all levels compared to $B_{3}$. Among the time-invariant schemes $B_{2}$ seemed to be slightly better than $B_{1}$ in a $24 \mathrm{~h}$ forecast at all levels. In a $48 \mathrm{~h}$ forecast, the RMS errors of $u$ and $v$ for $B_{1}$ at 850 and $500 \mathrm{hPa}$ are less than $B_{2}$, and the error of $Z$ for $B_{2}$ was less at all levels compared to $B_{1}$. We infer that $B_{4}$ has comparatively less RMS errors. 
Table 3. 24 and $48 \mathrm{~h}$ RMS errors of $u, v\left(\mathrm{~ms}^{-1}\right.$ ) and $Z(\mathrm{~m})$ at 850,500 and $200 \mathrm{hPa}$ levels for experiments $B_{1}, B_{2}, B_{3}$ and $B_{4}$.

\begin{tabular}{|c|c|c|c|c|c|c|c|c|c|}
\hline \multirow{2}{*}{$\begin{array}{l}\text { Level } \\
(\mathrm{hPa})\end{array}$} & \multirow[b]{2}{*}{ Variable } & \multicolumn{4}{|c|}{$24 \mathrm{~h}$} & \multicolumn{4}{|c|}{$48 \mathrm{~h}$} \\
\hline & & $B_{1}$ & $B_{2}$ & $B_{3}$ & $B_{4}$ & $B_{1}$ & $B_{2}$ & $B_{3}$ & $B_{4}$ \\
\hline \multirow{3}{*}{850} & $u$ & 3.6 & 3.5 & 3.4 & $3 \cdot 1$ & $5 \cdot 8$ & 5.9 & $4 \cdot 3$ & 4.4 \\
\hline & $v$ & $3 \cdot 2$ & $3 \cdot 3$ & $2 \cdot 9$ & 3.0 & $3 \cdot 1$ & $3 \cdot 6$ & $3 \cdot 1$ & $3 \cdot 3$ \\
\hline & $Z$ & $40 \cdot 8$ & $40 \cdot 3$ & $26 \cdot 3$ & $26 \cdot 5$ & $67 \cdot 2$ & $55 \cdot 6$ & 34.6 & $27 \cdot 7$ \\
\hline \multirow{3}{*}{500} & $u$ & $3 \cdot 1$ & 2.9 & $2 \cdot 6$ & $2 \cdot 4$ & 4.6 & $4 \cdot 7$ & 3.5 & $3 \cdot 4$ \\
\hline & $v$ & 2.9 & $2 \cdot 8$ & $2 \cdot 1$ & 1.9 & 3.8 & $3 \cdot 7$ & $3 \cdot 0$ & 2.8 \\
\hline & $Z$ & $47 \cdot 1$ & 47.5 & $28 \cdot 5$ & $30 \cdot 1$ & 86.7 & $70 \cdot 5$ & $43 \cdot 1$ & 36.5 \\
\hline \multirow{3}{*}{200} & $u$ & 5.0 & $4 \cdot 7$ & $4 \cdot 7$ & $4 \cdot 4$ & 7.2 & $7 \cdot 2$ & $5 \cdot 2$ & $5 \cdot 3$ \\
\hline & $v$ & $4 \cdot 8$ & $4 \cdot 5$ & $4 \cdot 5$ & $4 \cdot 1$ & $4 \cdot 4$ & $4 \cdot 4$ & $3 \cdot 8$ & 3.9 \\
\hline & $Z$ & $73 \cdot 3$ & $68 \cdot 7$ & $50 \cdot 5$ & 48.8 & $122 \cdot 9$ & $101 \cdot 3$ & $72 \cdot 7$ & $64 \cdot 1$ \\
\hline
\end{tabular}

(ii) Track of the depression: The predicted tracks of the monsoon depression at $850 \mathrm{hpa}$ of $B_{1}, B_{2}, B_{3}$ and $B_{4}$ are shown in figure 4 . The observed track is also shown for comparison. We find that the time-invariant schemes $B_{1}$ and $B_{2}$ show faster movement in the first $24 \mathrm{~h}$ than the time-dependent schemes $B_{3}$ and $B_{4}$. The track of $B_{4}$ shows a westward movement along the observed track and tracks of $B_{1}, B_{2}$ and $B_{3}$ show west-northwestward movement in the first $24 \mathrm{~h}$. In the next $24 \mathrm{~h} B_{3}$ and $B_{4}$ show faster movement than the time-invariant schemes. During this period, only the track of $B_{4}$ has a northerly component of motion similar to the observed while the tracks of other schemes have a southerly component of movement. Thus, the track of $B_{4}$ was found to be comparatively closer to that observed, although the initial movement was quite slow. Krishnamurti et al (1989) found a predicted track very close to that observed with the use of their so-called 'perfect boundary conditions' based on observed data analyses in FSU high resolution regional model.

(iii) Phase speed: The predicted phase speeds of the depression at $850 \mathrm{hPa}$ for all the four boundary schemes are shown in table 4 . The observed phase speeds are also shown in the same table for comparison. In the first $24 \mathrm{~h}$ the predicted phase speed of $B_{1}$ was close to the observed phase speed while the phase speeds of other schemes were less. The much slower movement of the depression in $B_{3}$ and $B_{4}$ in the first $24 \mathrm{~h}$ was reflected in their phase speeds being less than half the observed value. In the subsequent $24 \mathrm{~h}$, the phase speeds of $B_{3}$ and $B_{4}$ were comparable to those observed and those of $B_{1}$ and $B_{2}$ were lower.

(iv) Rainfall: The accumulated $48 \mathrm{~h}$ rainfall produced by $B_{1}, B_{2}, B_{3}$ and $B_{4}$ is shown in figure 5 . The accumulated rainfall at the northern and eastern boundaries are much reduced in $B_{2}$ and $B_{4}$ when compared with $B_{1}$ and $B_{3}$. This is due to the reduction of spurious divergence at the boundaries in $B_{2}$ and $B_{4}$. The reduction of divergence at the boundaries in $B_{2}$ and $B_{4}$ could be attributed to the application of sponge damping. However, the rainfall distribution well inside the boundary region is similar in all the four boundary schemes. Thus, the reduction of spurious divergence at the boundary does not appear to have a significant impact on the interior forecast. Kurihara $e^{2}$ al (1989) have also obtained a similar reduction in rainfall at the boundaries in their study with a version of the radiation boundary condition. Thus, $B_{2}$ and $B_{4}$ seem to handle the spurious divergence at the boundaries more effectively. 

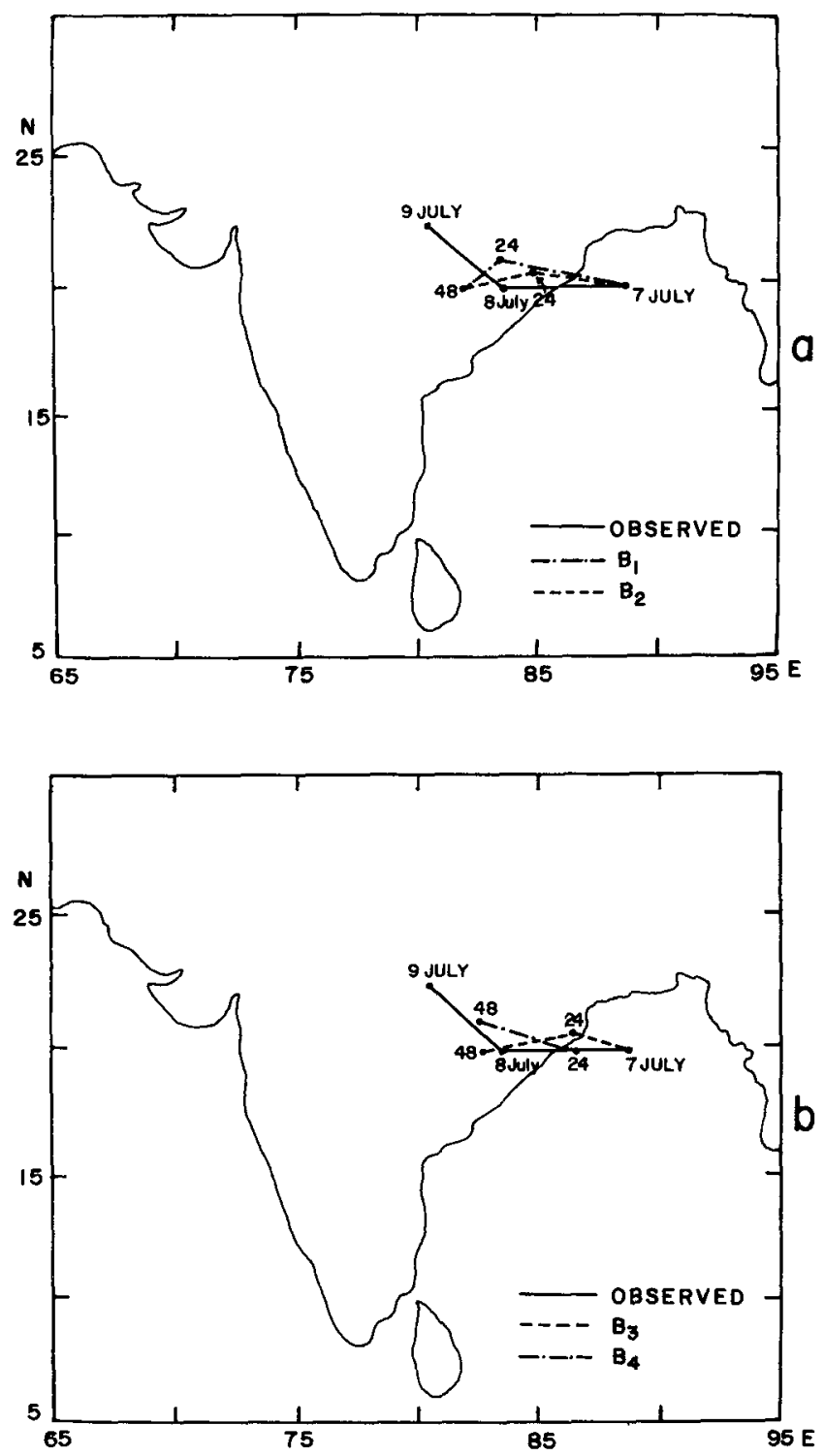

Figure 4. Predicted track of the monsoon depression at $850 \mathrm{hPa}$ level for (a) $B_{1}$ and $B_{2}$ schemes and (b) $B_{3}$ and $B_{4}$ schemes.

Table 4. Predicted and observed phase speeds of the monsoon depression at $850 \mathrm{hPa}$.

\begin{tabular}{rccccc}
\hline & \multicolumn{4}{c}{ Phase speed $(\mathrm{km} / 24 \mathrm{~h})$} \\
\cline { 2 - 5 }$T(\mathrm{~h})$ & $B_{1}$ & $B_{2}$ & $B_{3}$ & $B_{4}$ & Observed \\
\hline $0-24$ & 570 & 410 & 250 & 240 & 560 \\
$24-48$ & 200 & 325 & 400 & 420 & 420 \\
\hline
\end{tabular}



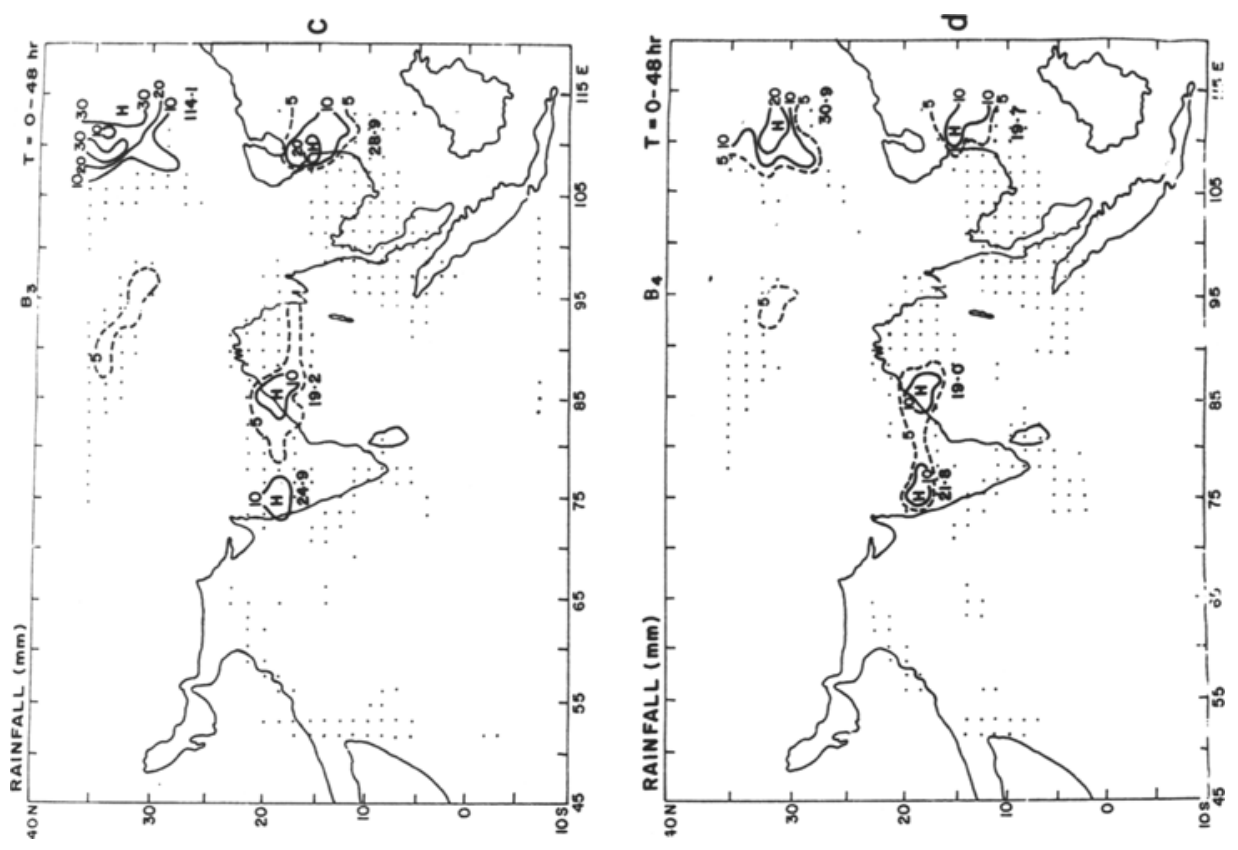

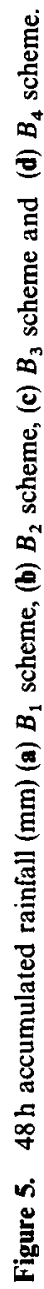


The results presented in $\S 5$ reveal that the time-dependent tendency modification scheme $\left(B_{4}\right)$ is a superior lateral boundary condition for the model.

\section{Prediction with revised version of the model}

The study on cumulus convection discussed in $\$ 4$ reveals that the Anthes (1977) scheme in Experiment 2 (EX2/AN77) scheme produced better forecasts. Similarly, from the study on lateral boundary conditions discussed in $\S 5$ it was found that the time-dependent tendency modification scheme $\left(B_{4}\right)$, based on large-scale tendencies obtained from observed data produced better forecasts. A prediction experiment was carried out with the revised version of the model incorporating the EX2/AN77 scheme of convection and $B_{4}$ scheme for lateral boundary conditions.

\subsection{Forecast results}

The revised version of the model was integrated up to $48 \mathrm{~h}$ using input data of 7 July 1979. As the result has been discussed in detail in $\$ \$ 4$ and 5 , the salient features of the forecasts are presented below.

(i) Track of the depression: The predicted and observed tracks of the monsoon depression are shown in figure 6. It can be seen that the predicted track of the depression is quite close to that observed although the speed of movement was slower. Compared to the tracks in the previous experiments, this was the best predicted track.

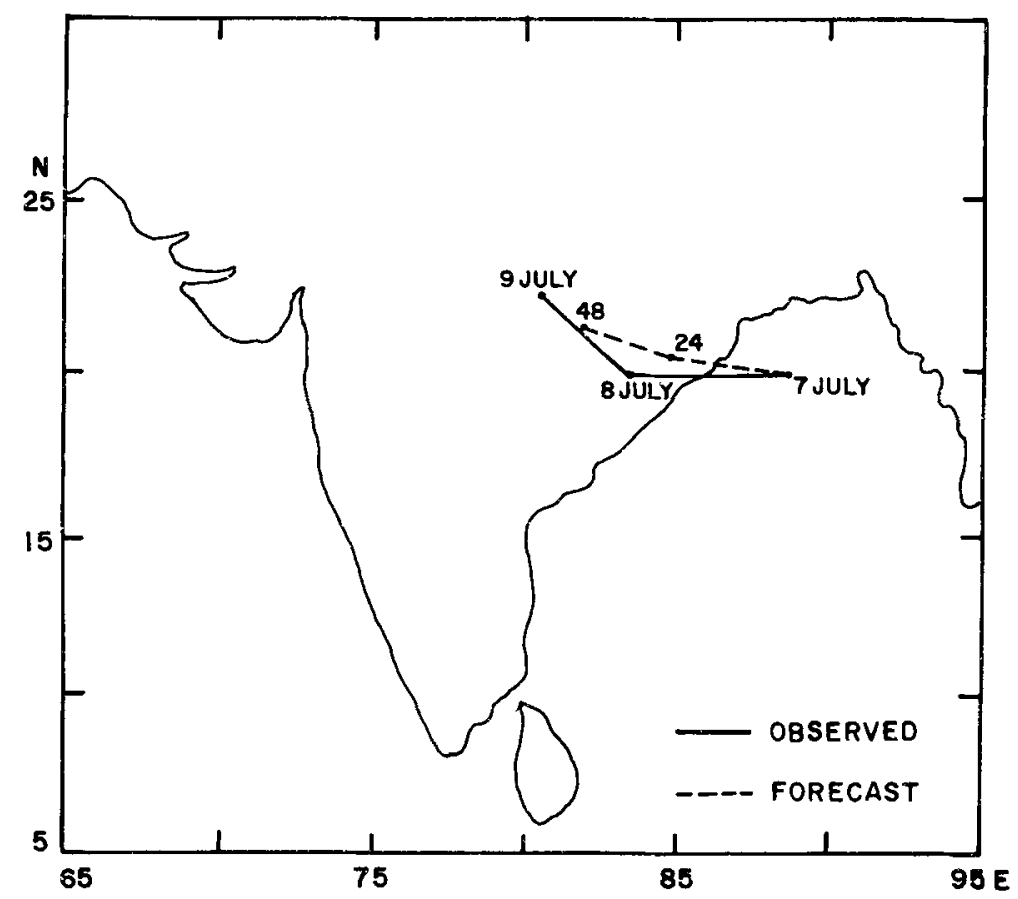

Figure 6. Predicted track of the monsoon depression at $850 \mathrm{hPa}$ level with revised version of the model. 
Table 5. 24 and $48 \mathrm{~h}$ RMS errors of $u, v\left(\mathrm{~ms}^{-1}\right)$ and $Z(\mathrm{~m})$ at 850,500 and $200 \mathrm{hPa}$ levels with revised version of the model.

\begin{tabular}{lcrr}
\hline $\begin{array}{l}\text { Level } \\
\text { (hPa) }\end{array}$ & Variable & $24 \mathrm{~h}$ & $48 \mathrm{~h}$ \\
\hline & $u$ & $3 \cdot 1$ & $4 \cdot 1$ \\
850 & $v$ & $2 \cdot 9$ & $3 \cdot 1$ \\
& $Z$ & $25 \cdot 9$ & 27.6 \\
& $u$ & $2 \cdot 2$ & 3.6 \\
500 & $v$ & $2 \cdot 0$ & $2 \cdot 8$ \\
& $Z$ & 29.1 & 34.8 \\
& $u$ & 4.5 & $5 \cdot 1$ \\
200 & $v$ & 3.9 & 4.0 \\
& $Z$ & 47.9 & 64.5 \\
\hline
\end{tabular}

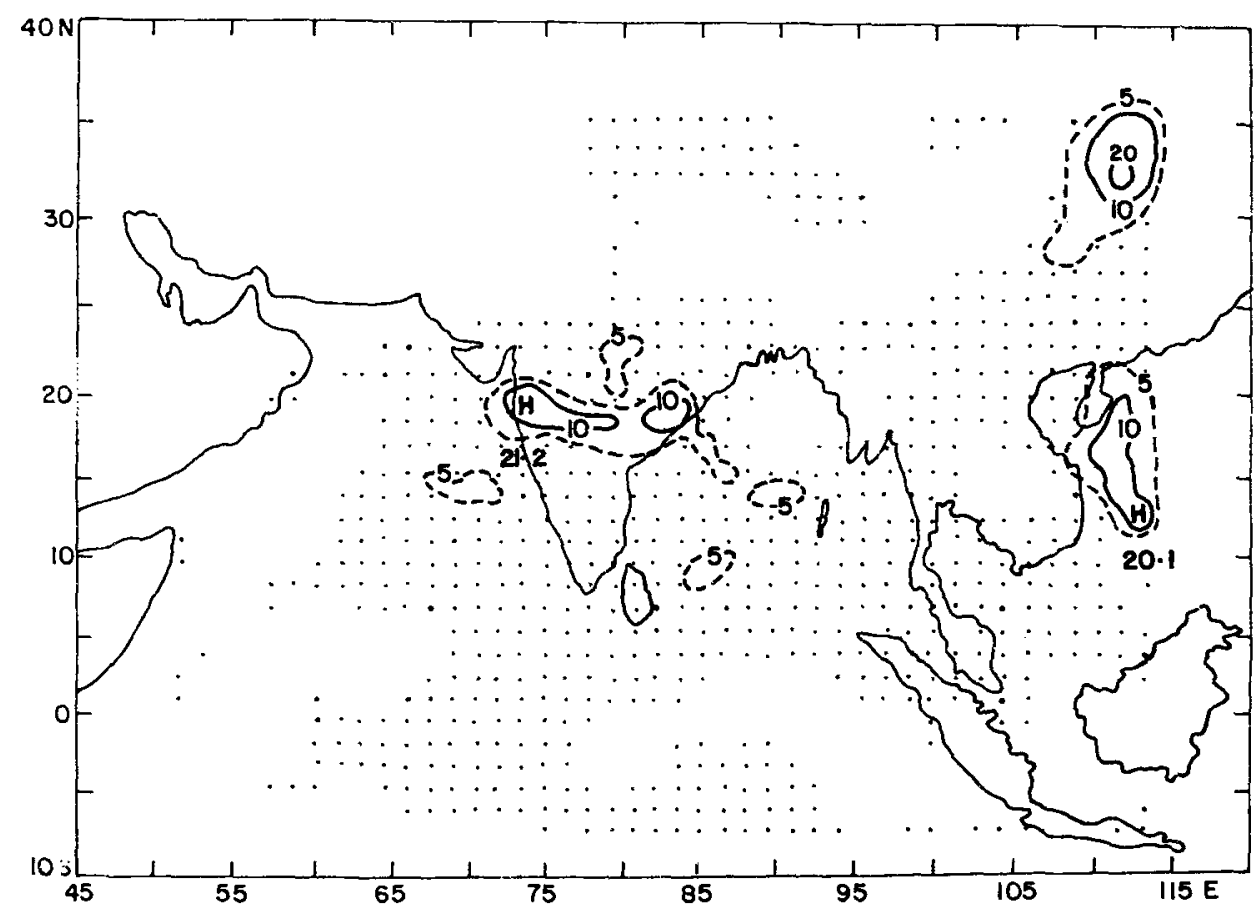

Figure 7. Predicted rainfall $(\mathrm{mm})$ for the period $T=12-36 \mathrm{~h}$ with revised of the model.

(ii) RMS errors: The RMS errors of $u$ and $v$ components of wind and geopotential height at 850,500 and $200 \mathrm{hPa}$ levels are shown in table 5 . In general, the RMS errors of all the three variables are lower at all levels compared to other experiments reported in this paper.

(iii) Rainfall: The predicted rainfall rates $(12-36 \mathrm{~h})$ are shown in figure 7 . It can be seen that the areal distribution of rainfall is predicted well. In this case there are two rainfall maxima, one near $84^{\circ} \mathrm{E}, 19^{\circ} \mathrm{N}$ of $10 \mathrm{~mm}$ and another of $21.2 \mathrm{~mm}$ near $73.5^{\circ} \mathrm{E}$, and $20^{\circ} \mathrm{N}$. The spurious rainfall amounts near the eastern boundary are reduced. 


\section{Conclusions}

Based on a case study of numerical prediction of one depression we reach the following conclusions. The study on cumulus convection revealed that inclusion of the Kuo (1974) scheme with Anthes (1977) criteria for computing the moistening parameter $b$ produced better forecasts. The study also suggests that there should be a check on the environmental mean relative humidity of the cloud layer for invoking convection in the model so as to avoid spurious forecasts. The study on lateral boundary conditions suggests that the time-dependent tendency modification scheme of Perkey and Kreitzberg (1976) based on the large-scale tendencies from 12-hourly real data analyses was a better scheme. This result emphasizes the importance of using global models to provide lateral boundary conditions for operational regional models. Furthermore, the revised version of the model incorporating an improved version of convection and tendency modification scheme for lateral boundary conditions produced overall improved forecasts.

\section{Acknowledgements}

The authors are thankful to Shri D R Sikka for the necessary support. Thanks are also due to Drs S K Mishra and S Rajamani for their valuable comments. Initially the Computer codes were developed and tested on ND-560 Computer System at IITM. Final computations were done on the CRAY-XMP/14 Computer System at NCMRWF, New Delhi.

\section{References}

Anthes R A 1977 A cumulus parameterization scheme utilizing a one-dimensional cloud model; Mon. Weather Rev. $105270-286$

Arakawa A and Mintz Y 1974 The UCLA atmospheric general circulation model; Notes distributed at Workshop 26 March-4 April 1974, University of California, Los Angeles

Arakawa A and Lamb V R 1977 Computational design of the basic dynamical processes of the UCLA general circulation model; Methods in computational physics (New York: Academic Press) pp 174-265

Arunkumar 1989 Documentation of the FSU limited area model; FSU Rept. No. 89-4, Dept. Meteorol., FSU, Tallahassee, Florida pp 302

Asselin R 1972 Frequency filter for time integrations; Mon. Weather Rev. 100 487-490

Davies H C 1983 Limitations of some common lateral boundary schemes used in regional NWP models; Mon. Weather Rev. 111 1001-1012

Grell G A, Kuo Y H and Pasch R J 1991 Semiprognostic tests of cumulus parameterization schemes in the middle latitudes; Mon. Weather Rev. 119 5-31

Kanamitsu M, Tada K, Kudo T, Sato N and Isa S 1983 Description of the JMA operational spectral model; J. Meteorol. Soc. Jpn. Ser. II 61 812-827

Krishnamurti T N, Ramanathan Y, Pan H L, Pasch R J and Molinari J 1980 Cumulus parameterization and rainfall rates I; Mon. Weather Rev. $108465-472$

Krishnamurti T N, Low-Nam S and Pasch R 1983a Cumulus parameterization and rainfall rates II; Mon. Weather Rev. $111815-828$

Krishnamurti T N, Cocke S, Pasch R and Low-Nam S 1983b Precipitation estimates from raingauge and satellite observations; Rept. No. 83-7, Dept. Meteorol., FSU, Tallahassee, Florida, pp 373

Krishnamurti T N, Kumar A, Yap K S, Dastoor A P, Davidson N and Sheng J 1989 Performance of a high resolution mesoscale tropical prediction model; Dept. Meteorol., FSU, Tallahassee, Florida, pp 123 
Kuo H L 1965 On formation and intensification of tropical cyclones through latent heat release by cumulus convection; J. Atmos. Sci. 22 40-63

Kuo H L 1974 Further studies of the parameterization of the influence of cumulus convection on large scale flow; J. Atmos. Sci. 31 1232-1240

Kurihara Y, Keer C L and Bender M A 1989 An improved numerical scheme to treat open lateral boundary of a regional model; Mon. Weather Rev. 117 2714-2722

Perkey D J and Kreitzberg C W 1976 A time-dependent lateral boundary scheme for limited-area primitive equation models; Mon. Weather Rev. 104 746-755

Singh S S, Vaidya S S and Rajagopal E N 1990 A limited area model for monsoon prediction; Adv. Atmos. Sci. 7 111-126

Slingo J M, Mohanty U C, Tiedtke M and Pearce R P 1988 Prediction of the 1979 summer monsoon onset with modified parameterization schemes; Mon. Weather Rev. 116 328-346

Sundstrom A and Elvius T 1979 Computational problems related to limited area modelling; Numerical methods used in atmospheric models, Vol II, GARP Publ. Ser. No. 17, ICSU/WMO, pp 381-416 